\title{
Psychological factors determine depressive symptomatology after stroke
}

Citation for published version (APA):

van Mierlo, M. L., van Heugten, C. M., Post, M. W., de Kort, P. L., \& Visser-Meily, J. M. (2015).

Psychological factors determine depressive symptomatology after stroke. Archives of Physical Medicine and Rehabilitation, 96(6), 1064-1070. https://doi.org/10.1016/j.apmr.2015.01.022

Document status and date:

Published: 01/06/2015

DOI:

10.1016/j.apmr.2015.01.022

Document Version:

Publisher's PDF, also known as Version of record

Document license:

Taverne

Please check the document version of this publication:

- A submitted manuscript is the version of the article upon submission and before peer-review. There can be important differences between the submitted version and the official published version of record.

People interested in the research are advised to contact the author for the final version of the publication, or visit the DOI to the publisher's website.

- The final author version and the galley proof are versions of the publication after peer review.

- The final published version features the final layout of the paper including the volume, issue and page numbers.

Link to publication

\footnotetext{
General rights rights.

- You may freely distribute the URL identifying the publication in the public portal. please follow below link for the End User Agreement:

www.umlib.nl/taverne-license

Take down policy

If you believe that this document breaches copyright please contact us at:

repository@maastrichtuniversity.nl

providing details and we will investigate your claim.
}

Copyright and moral rights for the publications made accessible in the public portal are retained by the authors and/or other copyright owners and it is a condition of accessing publications that users recognise and abide by the legal requirements associated with these

- Users may download and print one copy of any publication from the public portal for the purpose of private study or research.

- You may not further distribute the material or use it for any profit-making activity or commercial gain

If the publication is distributed under the terms of Article $25 \mathrm{fa}$ of the Dutch Copyright Act, indicated by the "Taverne" license above, 


\title{
Psychological Factors Determine Depressive Symptomatology After Stroke
}

\author{
Maria L. van Mierlo, MSc, ${ }^{a}$ Caroline M. van Heugten, PhD, ${ }^{b, c}$ Marcel W. Post, PhD, \\ Paul L. de Kort, MD, PhD, ${ }^{\text {e }}$ Johanna M. Visser-Meily, MD, PhD ${ }^{a}$
}

From the ${ }^{a}$ Brain Center Rudolf Magnus and Center of Excellence for Rehabilitation Medicine, University Medical Center Utrecht and De Hoogstraat Rehabilitation, Utrecht; ${ }^{b}$ Department of Psychiatry and Neuropsychology, School for Mental Health and Neuroscience, and ${ }^{c}$ Department of Neuropsychology and Psychopharmacology, Maastricht University, Maastricht; ${ }^{d}$ Department of Rehabilitation Medicine, Center for Rehabilitation, University of Groningen, University Medical Center Groningen, Groningen; and ${ }^{e}$ Department of Neurology, St. Elisabeth Hospital, Tilburg, The Netherlands.

\begin{abstract}
Objective: To identify psychological factors related to poststroke depressive symptoms.

Design: Cross-sectional study, with patients assessed at 2 months poststroke.

Setting: Patients with stroke from 6 general hospitals.

Participants: Stroke patients $(\mathrm{N}=344$; mean age $\pm \mathrm{SD}, 66.9 \pm 12.3 \mathrm{y})$.

Interventions: Not applicable.

Main Outcome Measures: The presence of clinical depressive symptoms was determined with the depression subscale of the Hospital Anxiety and Depression Scale 2 months poststroke. Psychological factors assessed were extraversion, neuroticism, optimism, pessimism, self-efficacy, helplessness, acceptance, perceiving benefits, proactive coping, and passive coping.

Results: Bivariate correlations and multivariate backward logistic regression were used to analyze associations between psychological factors and poststroke depressive symptoms, accounting for demographic and stroke-related factors. More neuroticism, pessimism, passive coping, and helplessness, and less extraversion, optimism, self-efficacy, acceptance, perceived benefits, and proactive coping were bivariately associated with the presence of depressive symptoms. Multivariate logistic regression analysis showed that more helplessness (odds ratio $[\mathrm{OR}]=1.17)$ and passive coping $(O R=1.19)$ and less acceptance $(O R=.89)$ and perceived benefits $(O R=.89)$ were independently significantly associated with the presence of poststroke depressive symptoms (Nagelkerke $R^{2}=.49$ ).

Conclusions: We found a relationship between psychological variables and the presence of depressive symptoms 2 months poststroke. It is important to take these factors into account during poststroke rehabilitation.
\end{abstract}

Archives of Physical Medicine and Rehabilitation 2015;96:1064-70

(C) 2015 by the American Congress of Rehabilitation Medicine

Depressive symptoms are common after stroke and have a profound influence on functioning and quality of life. ${ }^{1}$ Reported prevalence rates of poststroke depressive symptoms (PSDS) in the acute phase range from $5 \%$ to $54 \%$, and prevalence rates of major depression 2 years poststroke are still around $20 \% .^{1,2}$

The etiology of poststroke depression is still unclear. Some researchers have proposed a biological mechanism in which

Supported by the VSBfund (grant no. 89000004).

Disclosures: none. depression is caused by brain damage disrupting neural circuits involved in mood regulation. ${ }^{3}$ Others suggest that depression is caused by a psychological reaction to the social and psychological stressors associated with stroke. ${ }^{4}$ There are several arguments for both theories, and poststroke depression is most likely to be multifactorial in origin, a combination of both biological and psychological mechanisms. $^{2}$

Until now, research into the determinants of PSDS has focused mainly on stroke-related factors (eg, lesion location, severity of neurologic damage) and demographic factors (eg, age, sex). ${ }^{5}$ Prognostic studies found that stroke severity, ${ }^{6}$ lesion location, ${ }^{7,8}$ functional 
status, ${ }^{9}$ younger age, ${ }^{10}$ sex,${ }^{11,12}$ cognitive dysfunction, ${ }^{12}$ and history of depression ${ }^{13}$ explained only a small part of the variance of PSDS.

This implies that additional variables, such as psychological factors, should be considered. The influence of psychological factors on PSDS is of growing interest. It is assumed that the way patients think about and perceive their illness accounts for much of the individual differences in their physical and psychological health status. ${ }^{14}$ The Common Sense Model (CSM) by Leventhal describes part of this adaptation process and assumes that when people are confronted with a chronic illness, they try to make sense of it by creating a cognition of it, which influences their coping styles and hence their illness adaptation. ${ }^{15}$ In addition, a person's stable characteristics, such as personality traits, are assumed to influence the process of creating the illness cognitions. ${ }^{15,16}$ Thus, the influence of personality traits on depressive symptoms is mediated through illness cognitions and coping styles.

Some research has been done on the influence of psychological factors on PSDS. Associations with personality traits such as neuroticism, extraversion, and conscientiousness have been evaluated in a number of studies, ${ }^{5,17-19}$ and only high levels of neuroticism were found to be related to higher levels of PSDS. However, these studies used small samples and therefore lacked statistical power. Optimism has only once been investigated as a determinant of PSDS, and was not found to be a significant predictor of PSDS, ${ }^{19}$ unlike what was found by studies in other diagnostic groups. ${ }^{20}$ General self-efficacy has not been associated with PSDS, but is a strong predictor of depression and quality of life in other diagnostic groups, such as cancer ${ }^{21}$ and spinal cord injury. ${ }^{22}$ A specific form of self-efficacy, self-care self-efficacy, was associated with depression in stroke patients. ${ }^{23}$ The influence of illness cognitions on PSDS has been investigated in 2 studies, ${ }^{24,25}$ which found that several illness cognitions, such as acceptance of the illness, are associated with PSDS. However, other illness cognitions, such as helplessness and perceiving benefits, also need to be investigated for their influence on PSDS. Several coping styles, such as avoidance coping, have been found to be related to depressive symptoms in individuals with stroke. ${ }^{19,26,27}$ Proactive coping was found to correlate with healthrelated quality of life. ${ }^{28}$ Since, the evidence is, however, still limited, there is a need to further examine the associations between various psychological factors and PSDS.

Ultimately, taking the influence of psychological factors into account should result in more personalized rehabilitation treatment. The objective of this study was therefore to examine the influence of a broad spectrum of psychological factors on PSDS 2 months poststroke, namely personality traits (extraversion, neuroticism, optimism, pessimism, self-efficacy), illness cognitions (helplessness, acceptance, perceiving benefits), and coping styles (proactive coping, passive coping), while controlling for the influence of demographic and stroke-related factors.

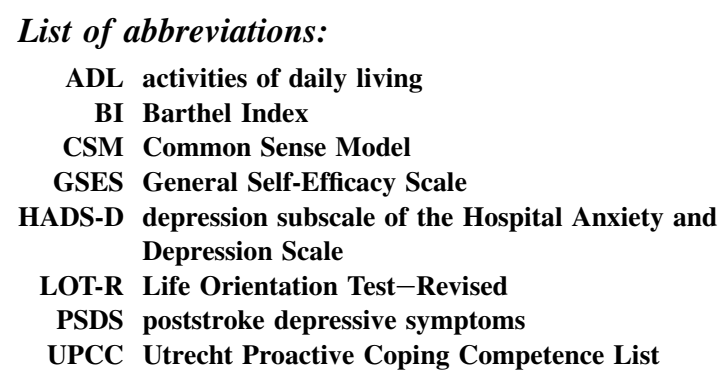

\section{Methods}

\section{Design and procedure}

The current study is part of the longitudinal Restore4Stroke Cohort study, in which new stroke patients are followed up for 2 years. ${ }^{29}$ Six general hospitals in the Netherlands participated, and stroke patients were recruited between March 2011 and March 2013. The medical ethics committees of all participating hospitals approved the Restore4Stroke Cohort study, and informed consent was obtained from all included patients. The present study reports data from stroke onset and 2 months poststroke.

The first assessment ( $\mathrm{t} 1)$ regarded demographic and strokerelated factors. After informed consent had been given, the strokerelated factors, assessed by the neurologist on day 4, were extracted from the medical charts. Information on demographic factors was obtained from the patient or family members. In the second assessment, which took place 2 months poststroke ( $\mathrm{t} 2)$, patients were asked to complete the self-report scales for depression and psychological factors, and cognitive screening was conducted by trained research assistants.

\section{Participants}

Stroke patients were eligible for this study if they were $\geq 18$ years of age, had a clinically confirmed diagnosis of stroke (ischemic or intracerebral hemorrhagic lesion), and had suffered their stroke within the last 7 days.

Patients were excluded if they (1) had another serious health condition that could be expected to interfere with the study outcomes; (2) had already been dependent regarding activities of daily living (ADL) before their stroke, as defined by a Barthel Index (BI) of $\leq 17^{30}$; (3) had insufficient command of the Dutch language to understand and complete the questionnaires, based on clinical judgment; or (4) had already been experiencing cognitive decline before their stroke, as defined by a score of $\geq 1$ on the Heteroanamnesis List Cognition. ${ }^{31}$

\section{Measures}

\section{Dependent variable: presence of depressive symptoms}

The presence of depressive symptoms 2 months poststroke was assessed using the depression subscale of the Hospital Anxiety and Depression Scale (HADS-D). ${ }^{32,33}$ The Hospital Anxiety and Depression Scale has shown good psychometric properties ${ }^{33}$ and is commonly used for stroke patients. ${ }^{34}$

\section{Independent variables: demographic and stroke-related factors}

We collected data on sex, age, and level of education. For level of education we used the Dutch Verhage classification ranging from 1 (did not finish primary school) to 7 (university graduation). ${ }^{35}$ The severity of the stroke was assessed with the National Institutes of Health Stroke Scale. ${ }^{36}$ ADL was assessed using the BI, which is a validated measure often used in stroke. ${ }^{30}$ Cognitive functioning was assessed using the Montreal Cognitive Assessment. ${ }^{37}$

\section{Independent variables: psychological factors}

Extraversion and neuroticism were assessed with 2 subscales of the Eysenck Personality Questionnaire Revised Short Scale. ${ }^{38}$ The extraversion (eg, "Are you a talkative person?") and neuroticism (eg, "Does your mood often go up and down?") scales both consist of 
12 items with dichotomous (yes/no) response options. A higher sum score indicates a higher level of extraversion or neuroticism, respectively. The internal consistencies of the neuroticism and extraversion scales are satisfactory (Cronbach $\alpha$ coefficient in the present study was .83 for both scales). Optimism and pessimism were assessed with the Life Orientation Test-Revised (LOT-R). ${ }^{39}$ The LOT-R is a 6-item measure with 2 subscales that measure optimism (eg, "In uncertain times, I usually expect the best") and pessimism (eg, "If something can go wrong for me, it will"), respectively, with 3 items each. The LOT-R is scored on a 5-point response scale, ranging from 0 (strongly disagree) to 4 (strongly agree). Higher sum scores on the 2 subscales indicate a higher level of optimism or pessimism, respectively. The internal consistency for optimism in the present study was moderate (Cronbach $\alpha$ coefficient, .62), while that for pessimism was sufficient (Cronbach $\alpha$ coefficient, .72). Self-efficacy was assessed with the General Self-Efficacy Scale (GSES). ${ }^{40}$ The GSES consists of 10 items scored on a 4-point scale, ranging from "not at all true" to "exactly true" (eg, "I am confident that I could deal efficiently with unexpected events"). A higher sum score indicates a higher level of self-efficacy. Psychometric properties of the GSES scale are satisfactory to good. ${ }^{40}$ Internal consistency in the present study was high (Cronbach $\alpha$ coefficient, .92).

Illness cognitions were measured with the Illness Cognition Questionnaire. ${ }^{14}$ This scale consists of 18 items that are scored on a 4-point scale ranging from 1 (not at all) to 4 (completely). The items belong to 1 of 3 subscales: helplessness (eg, "My illness frequently makes me feel helpless"), acceptance (eg, "I can accept my illness well"), and perceived benefits (eg, "My illness has made life more precious to me"), each measured with 6 items and a scoring range of 6 to 24 . The Illness Cognition Questionnaire is a reliable instrument to assess illness cognitions in patients with several chronic diseases, such as rheumatoid arthritis and multiple sclerosis. ${ }^{14}$ The internal consistencies in the present study were high: Cronbach alpha coefficients were .88 for the helplessness and acceptance subscales and .83 for the perceived benefits subscale.

Proactive coping competencies were assessed with the Utrecht Proactive Coping Competence List (UPCC). ${ }^{41}$ The UPCC consists of 21 items scored on a 4-point scale, with scores of competence ranging from "not at all" to "very," resulting in a mean score ranging from 1 to 4 , with a higher score indicating a higher level of proactive coping. An example question is, "To what extent do you have the capacity to recognize signals that something might go wrong?" The UPCC has shown good psychometric properties in stroke patients. ${ }^{28}$ Internal consistency in the present study was high (Cronbach $\alpha$ coefficient, .93). Passive coping was assessed with the passive reaction pattern subscale of the Utrecht Coping List. $^{42}$ This subscale consists of 7 items that are scored on a 4-point scale ranging from "seldom" to "very often" (eg, "take refuge in fantasies"). A higher sum score indicates a higher level of passive coping. The internal consistency of this subscale in the present study was sufficient (Cronbach $\alpha$ coefficient, .72), and the test-retest reliability is high (correlation coefficient, .76). ${ }^{42}$

\section{Statistical analysis}

Data were analyzed with the SPSS statistical software package (version 21). ${ }^{a}$ Descriptive statistics were used to describe patients' characteristics.

Scores on the HADS-D were dichotomized into "no depressive symptoms" (HADS-D $<8$ ) and "depressive symptoms" (HADS$\mathrm{D} \geq 8) .{ }^{33}$ Bivariate logistic regression analyses were used to select bivariately significant determinants of PSDS $(P<.05)$. Sex, age, and education were entered as demographic factors, and severity of stroke, ADL independence 2 months poststroke, and cognitive functioning 2 months poststroke were entered as stroke-related factors. The level of education was dichotomized into low (1-5) and high (6-7). ${ }^{43}$ The BI score was dichotomized into "dependent" $(\mathrm{BI}<18)$ and "independent" ( $\mathrm{BI} \geq 18)$. Scores on the psychological questionnaires were entered as continuous variables in the analyses.

Bivariately significant factors were tested for multicollinearity (correlation coefficient, $>0.7$ ), which did not reveal any problems. Demographic variables, stroke-related factors, and the bivariately significant psychological factors were used in a multivariate hierarchical backward logistic regression analysis. Ensuring that the demographic and stroke-related factors could not be removed from the model, we used the Enter method in the first 2 blocks (demographic and stroke-related factors), and the stepwise backward method (likelihood ratio) in the last block ( $P$ in $.05, P$ out 0.1 ). Goodness of fit of the multivariate model was tested with the Hosmer-Lemeshow test. In addition, odds ratios and their $95 \%$ confidence intervals were reported. The critical value of $\alpha$ was set at .05.

\section{Results}

\section{Participants}

A total of 395 stroke patients were included in the Restore4Stroke Cohort study. The data of 344 participants $(87 \%)$ were available for analysis. Three participants had died and 18 refused further participation. Furthermore, 30 participants could not take part in the $\mathrm{t} 2$ assessment, 5 because of severe aphasia and 25 because of their general physical condition.

The mean age \pm SD at the onset of stroke was $66.9 \pm 12.3$ years; $36 \%$ of the participants were women, and $93 \%$ had suffered an ischemic stroke (table 1). Four days poststroke, their mean ADL score was 17.2. Seventy-three percent of the participants were discharged home after acute care hospitalization. The descriptive statistics of the psychological measures are presented in table 2.

\section{Depressive symptoms}

Two months poststroke, $21.5 \%$ of the participants experienced depressive symptoms. Of these patients, $71.6 \%$ had a score between 8 and 11 (mild), $17.7 \%$ had a score between 12 and 14 (moderate), and $10.7 \%$ had a score of $\geq 15$ (severe) on the HADS-D.

\section{Bivariate analysis}

Bivariate analysis showed that the presence of PSDS was associated with higher levels of neuroticism, pessimism, helplessness, and passive coping, and lower levels of extraversion, optimism, self-efficacy, acceptance, perceived benefits, and proactive coping (table 3).

None of the demographic factors were significantly associated with PSDS, and of the stroke-related factors only poorer cognitive functioning was associated with the presence of PSDS.

\section{Multivariate analysis}

The multivariate hierarchical backward logistic regression analysis showed that more helplessness and passive coping and less acceptance and perceived benefits were independently significantly associated with the presence of PSDS (see table 3). Nagelkerke $R^{2}$ 
Table 1 Patients' characteristics $(\mathrm{N}=344)$

\begin{tabular}{|c|c|}
\hline Characteristic & Values \\
\hline \multicolumn{2}{|l|}{ Demographic Factors } \\
\hline Sex (female) & 36 \\
\hline Age $(y)$ & $66.9 \pm 12.3$ \\
\hline Marital status, living together $(n=342)$ & 68.7 \\
\hline High education level $^{*}(n=342)$ & 26.9 \\
\hline \multicolumn{2}{|l|}{ Stroke-related factors } \\
\hline Ischemic stroke & 93 \\
\hline Left hemisphere $(n=343)$ & 39.9 \\
\hline Severity of stroke & $2.5 \pm 2.9$ \\
\hline No stroke symptoms (NIHSS 0 ) & 25 \\
\hline Minor stroke symptoms (NIHSS $1-4$ ) & 57.9 \\
\hline Moderate stroke symptoms (NIHSS 5-12) & 16.3 \\
\hline $\begin{array}{l}\text { Moderate to severe stroke symptoms } \\
\quad(\text { NIHSS } \geq 13)\end{array}$ & 0.9 \\
\hline ADL 4 d poststroke $(n=344)$ & $17.2 \pm 4.4$ \\
\hline ADL independent (BI 18-20) & 68.9 \\
\hline ADL dependent $(\mathrm{BI} \leq 17)$ & 31.1 \\
\hline ADL 2 mo poststroke $(n=343)$ & $19.3 \pm 2.03$ \\
\hline ADL independent (BI 18-20) & 91.0 \\
\hline ADL dependent $(\mathrm{BI} \leq 17)$ & 9.0 \\
\hline Cognitive functioning 2 mo poststroke $(n=339)$ & $23.5 \pm 4$ \\
\hline Normal cognition (MoCA $26-30$ ) & 32.2 \\
\hline Cognitively impaired (MoCA $\leq 25$ ) & 67.8 \\
\hline \multicolumn{2}{|l|}{ Destination after discharge from hospital } \\
\hline Home & 73.3 \\
\hline Rehabilitation center & 13.4 \\
\hline Nursing home & 13.4 \\
\hline
\end{tabular}

NOTE. Values are percentages or mean \pm SD.

Abbreviations: MoCA, Montreal Cognitive Assessment; NIHSS, National Institutes of Health Stroke Scale.

* Patients completed higher professional education or have a university degree.

of the final model was .49. The multivariate model showed a good fit (Hosmer-Lemeshow test, $P=.94$ ).

\section{Discussion}

Two months after stroke, $21.5 \%$ of the participants had depressive symptoms in the clinical range, most of whom had mild symptoms. All psychological factors investigated were bivariately related to the presence of depressive symptoms 2 months poststroke. More helplessness and passive coping and less acceptance and perceiving benefits were identified as independent predictors of the presence of PSDS 2 months poststroke.

This is the first study to investigate the influence of a broad range of psychological factors on PSDS. Among the personality traits, all factors were found to be predictors of PSDS in the bivariate analyses. This is not entirely in agreement with earlier research in stroke patients, as some factors that were found to be predictive in the present study, such as extraversion and optimism, were not found to be predictors in earlier stroke studies. The influence of illness cognitions on PSDS has been found in 2 other studies, ${ }^{24,25}$ and the relationship between illness cognitions and depressive symptoms has also been confirmed in patients with other diagnoses. ${ }^{44}$ The influence of passive coping on PSDS that we found is also in agreement with the literature. ${ }^{18,25,26}$ Whereas more active coping styles can reduce depressive mood, passive coping styles can increase feelings of depression. ${ }^{18}$
Table 2 Descriptive statistics of the psychological measures

\begin{tabular}{llclc}
\hline Psychological Factor & Measure & Actual Range & $\mathrm{N}$ & Mean \pm SD \\
\hline Extraversion & EPQ-RSS-E & $0-12$ & 340 & $7.1 \pm 3.2$ \\
Neuroticism & EPQ-RSS-N & $0-12$ & 341 & $3.6 \pm 3.1$ \\
Optimism & LOT-R & $2-12$ & 341 & $8.2 \pm 2.1$ \\
Pessimism & LOT-R & $0-12$ & 340 & $4.4 \pm 2.8$ \\
Self-efficacy & GSES & $10-40$ & 340 & $31.6 \pm 6.4$ \\
Helplessness & ICQ & $6-24$ & 341 & $11.9 \pm 4.9$ \\
Acceptance & ICQ & $6-24$ & 340 & $16.4 \pm 4.9$ \\
Perceived benefits & ICQ & $6-24$ & 339 & $15.0 \pm 4.8$ \\
Proactive coping & UPCC & $1-4$ & 340 & $3.1 \pm 0.6$ \\
Passive coping & UCL-P & $7-23$ & 341 & $10.5 \pm 2.8$ \\
\hline
\end{tabular}

Abbreviations: EPQ-RSS-E, Eysenck Personality Questionnaire Revised Short Scale-Extraversion; EPQ-RSS-N, Eysenck Personality Questionnaire Revised Short Scale-Neuroticism; ICQ, Illness Cognition Questionnaire; UCL-P, Utrecht Coping List.

According to the CSM, patients create illness cognitions of their illness when they are confronted with it. These cognitions lead to the use of different coping styles in order to adapt to the illness. Furthermore, a person's stable characteristics, such as personality traits, are assumed to influence the process of creating the illness cognition. ${ }^{14,15}$ In the present study we showed that personality traits, illness cognitions, and coping styles are associated with PSDS. An interesting topic for future research would be to investigate whether the relationships between these factors follow the path assumed in the CSM-that is, whether the influence of personality traits on depressive symptoms is mediated by illness cognitions and coping styles.

None of the demographic and stroke-related factors were significant determinants of PSDS in the bivariate analyses, except for cognitive functioning. This contrasts with the findings of other studies. $^{5-11,13}$ Our findings might be attributed to the high proportion $(82 \%)$ of participants who had suffered a minor stroke, experiencing no or minor stroke symptoms and being independent in ADL 2 months poststroke. On the other hand, a relatively high proportion of participants were cognitively impaired (68\%). It is interesting that even patients who have a mild stroke can be cognitively impaired after the stroke.

To optimize rehabilitation interventions for PSDS, we need to know which factors influence PSDS and which factors can be modified by means of therapy. Traditionally, it was assumed that personality traits, such as neuroticism, remain relatively stable throughout a person's lifespan. ${ }^{38,45}$ This assumption has been partly confirmed by studies showing that personality traits were indeed relatively stable over time, as reflected in test-retest correlations of personality measures. ${ }^{46}$ However, there is also increasing evidence that personality traits have the potential to change and develop during one's life. ${ }^{47}$ A study ${ }^{48}$ assessing an individualized stroke self-management intervention found positive results in terms of changing self-efficacy after stroke.

Studies ${ }^{4,50}$ in patients with other chronic diseases, such as inflammatory rheumatic diseases, have reported promising results concerning the possibility of modifying illness cognitions by means of multidisciplinary rehabilitation treatment and cognitive behavioral therapy. Research ${ }^{51}$ has also shown that patients with traumatic brain injury can be taught to make use of more adaptive coping styles, such as active problem-focused styles. A recent meta-analysis ${ }^{52}$ found moderate effectiveness of psychological treatment of depression in individuals with acquired brain injury, 
Table 3 Bivariate and multivariate logistic regression analyses of PSDS

\begin{tabular}{|c|c|c|c|c|c|c|c|c|c|c|}
\hline \multirow[b]{2}{*}{ Factors } & \multirow[b]{2}{*}{ Measure } & \multirow[b]{2}{*}{$\mathrm{N}$} & \multicolumn{4}{|c|}{ Bivariate Analysis } & \multicolumn{4}{|c|}{ Multivariate Analysis $(\mathrm{N}=334)$} \\
\hline & & & $\beta$ & SE & $P$ & Odds $(95 \% \mathrm{CI})$ & $\beta$ & SE & $P$ & Odds $(95 \% \mathrm{CI})$ \\
\hline \multicolumn{11}{|l|}{ Demographic factors } \\
\hline Sex (female) & & 344 & .39 & .27 & .147 & $1.47(.87-2.49)$ & -0.06 & .36 & .878 & $0.95(.47-1.92)$ \\
\hline Age & & 344 & -.00 & .01 & .837 & $1.00(.98-1.02)$ & -0.01 & .01 & .469 & $0.99(.96-1.02)$ \\
\hline Education (low) & & 342 & .65 & .33 & .051 & $1.92(1.00-3.69)$ & 0.54 & .44 & .212 & $1.72(.73-4.06)$ \\
\hline \multicolumn{11}{|l|}{ Stroke-related factors } \\
\hline Severity of stroke & NIHSS & 344 & -.01 & .05 & .916 & $1.00(.91-1.09)$ & -0.09 & .06 & .136 & $0.91(.81-1.03)$ \\
\hline ADL (dependent) & $\mathrm{BI}$ & 343 & .48 & .27 & .080 & $1.62(.95-2.76)$ & -0.07 & .62 & .907 & $0.93(.28-3.10)$ \\
\hline Cognitive functioning & MoCA & 339 & -.09 & .03 & $.006^{*}$ & $.92(.86-.98)$ & -0.02 & .05 & .663 & $0.98(.89-1.08)$ \\
\hline \multicolumn{11}{|l|}{ Psychological factors } \\
\hline Extraversion & EPQ-RSS-E & 340 & -.10 & .04 & $.021^{*}$ & $.91(.84-.99)$ & & & $\dagger$ & \\
\hline Neuroticism & EPQ-RSS-N & 341 & .30 & .05 & $\leq .001^{*}$ & $1.35(1.24-1.48)$ & 0.12 & .07 & .075 & $1.13(.99-1.29)$ \\
\hline Optimism & LOT-R & 341 & -.43 & .07 & $\leq .001^{*}$ & $.65(.57-.75)$ & & & $\dagger$ & \\
\hline Pessimism & LOT-R & 340 & .21 & .05 & $\leq .001^{*}$ & $1.24(1.13-1.36)$ & 0.14 & .07 & .050 & $1.15(1.00-1.31)$ \\
\hline Self-efficacy & GSES & 340 & -.08 & .02 & $\leq .001^{*}$ & $.92(.89-.96)$ & & & $\dagger^{\dagger}$ & \\
\hline Helplessness & ICQ & 341 & .20 & .03 & $\leq .001^{*}$ & $1.22(1.15-1.30)$ & 0.16 & .04 & $<.001^{*}$ & $1.17(1.08-1.28)$ \\
\hline Acceptance & ICQ & 340 & -.24 & .04 & $\leq .001 *$ & $.79(.74-.85)$ & -0.11 & .05 & $.023^{*}$ & $0.89(.81-.98)$ \\
\hline Perceived benefits & ICQ & 339 & -.14 & .03 & $\leq .001^{*}$ & $.87(.82-.92)$ & -0.12 & .05 & $.007^{*}$ & $0.89(.81-.97)$ \\
\hline Proactive coping & UPCC & 340 & -.95 & .22 & $\leq .001^{*}$ & $.39(.25-.59)$ & & & ${ }^{\dagger}$ & \\
\hline Passive coping & UCL-P & 341 & .38 & .06 & $\leq .001^{*}$ & $1.46(1.31-1.64)$ & 0.17 & .08 & $.024^{*}$ & $1.19(1.02-1.38)$ \\
\hline Constant & & & & & & & -2.10 & & & \\
\hline
\end{tabular}

Abbreviations: $\beta$, standardized regression coefficient; CI, confidence interval; EPQ-RSS-E, Eysenck Personality Questionnaire Revised Short ScaleExtraversion; EPQ-RSS-N, Eysenck Personality Questionnaire Revised Short Scale-Neuroticism; ICQ, Illness Cognition Questionnaire; MoCA, Montreal Cognitive Assessment; NIHSS, National Institutes of Health Stroke Scale.

* $P$ values are significant.

$\dagger$ Variables that were removed from the analysis using a backward procedure are indicated with a single dagger $(\dagger)$.

including stroke patients, suggesting the value of such interventions in rehabilitation practice.

\section{Study strengths}

This study has several strengths. First, it included a large group of patients who had had a stroke. Second, it investigated the influence of a combination of psychological factors on PSDS. Third, it examined a combination of demographic, stroke-related, and psychological factors to identify their influence on PSDS. This has resulted in a more complete overview of the factors that together determine PSDS 2 months poststroke.

\section{Study limitations}

Our results must be interpreted with the following limitations in mind. First, patients with an ischemic lesion were overrepresented in our cohort: $93 \%$ of the patients had an ischemic lesion, compared with $75 \%$ in the total stroke population in the Netherlands. ${ }^{53}$ This is probably a result of recruiting patients from general hospitals and not from academic hospitals. Another reason could be that hemorrhagic lesions are generally more severe, which means that fewer patients are able to receive and understand information about the study and agree to participate within 1 week after the onset of stroke. However, we do not think this overrepresentation of patients with ischemic stroke has led to problems regarding the generalizability of the results.

Second, this was a cross-sectional study in which both depressive symptoms and the psychological factors were assessed 2 months poststroke, so we were not able to determine causality.
Future research should focus on longitudinal designs assessing the psychological factors in the subacute phase and the experience of depressive symptoms in the chronic phase poststroke. This will provide more insight into potential causal relationships between psychological factors and depressive symptoms.

Third, it is difficult to differentiate between psychological factors and depressed mood. For instance, depressed mood may lead to a high score for pessimism. In our opinion, however, these factors are conceptually different from depressed mood, and the questionnaires used to measure psychological factors and depressive symptoms use very different statements. Examples of questions used for depressive symptoms include "I feel tense or "wound up"" and "I still enjoy the things I used to enjoy," while questions for neuroticism include "Do you worry too long after an embarrassing experience?" and those for acceptance include "I have learned to accept the limitations imposed by my illness." Furthermore, empirical research shows that the association between psychological factors and depressive symptoms is far from perfect, indicating that psychological factors and depression are at least partially distinct from each other. The literature shows that there are even psychological factors whose association with depressive symptoms in stroke has not yet been established. Earlier research ${ }^{18}$ did not find optimism to be associated with depressive symptoms, but in the present study it was.

\section{Conclusions}

This study shows the relevance of psychological factors for the presence of depressive symptoms 2 months poststroke. It is 
important to take these psychological factors into account during poststroke rehabilitation.

\section{Supplier}

a. SPSS statistical software package (version 21); IBM Corp.

\section{Keywords}

Depression; Mental health; Psychology; Rehabilitation; Stroke

\section{Corresponding author}

Johanna M. Visser-Meily, MD, PhD, University Medical Center Utrecht, PO Box 85500, 3508 GA Utrecht, The Netherlands. E-mail address: j.m.a.visser-meily@umcutrecht.nl.

\section{References}

1. Kouwenhoven SE, Kirkevold M, Engedal K, Kim HS. Depression in acute stroke: prevalence, dominant symptoms, and associated factors. A systematic literature review. Disabil Rehabil 2011;33:539-56.

2. Whyte EM, Mulsant BH. Post stroke depression: epidemiology, pathophysiology, and biological treatment. Biol Psychiatry 2002;52: 253-64.

3. Robinson R, Kubos K, Starr L, Rao K, Price TR. Mood disorders in stroke patients: importance of location of lesion. Brain 1984;107: 81-93.

4. Gainotti G, Azzoni A, Marra C. Frequency, phenomenology and anatomical-clinical correlates of major post-stroke depression. Br J Psychiatry 1999;175:163-7.

5. Aben I, Denollet J, Lousberg R, Verhey F, Wojciechowski F, Honig A. Personality and vulnerability to depression in stroke patients: a 1-year prospective follow-up study. Stroke 2002;33:2391-5.

6. Berg A, Palomaki H, Lehtihalmes M, Lonnqvist J, Kaste M. Poststroke depression: an 18-month follow-up. Stroke 2003;34:138-43.

7. Terroni L, Amaro E Jr, Iosifescu DV, et al. Stroke lesion in cortical neural circuits and post-stroke incidence of major depressive episode: a 4-month prospective study. World J Biol Psychiatry 2011;12: $539-48$.

8. Vataja R, Leppavuori A, Pohjasvaara T, et al. Poststroke depression and lesion location revisited. J Neuropsychiatry Clin Neurosci 2004; 16:156-62.

9. Van de Port IG, Kwakkel G, Bruin M, Lindeman E. Determinants of depression in chronic stroke patients: a prospective cohort study. Disabil Rehabil 2007;29:353-8.

10. Carota A, Berney A, Aybek S, et al. A prospective study of predictors of poststroke depression. Neurology 2005;64:428-33.

11. Schepers V, Post M, Visser-Meily A, van de Port I, Akhmouch M, Lindeman E. Prediction of depressive symptoms up to three years post-stroke. J Rehabil Med 2009;41:930-5.

12. Nys GM, van Zandvoort MJ, van der Worp HB, et al. Early cognitive impairment predicts long-term depressive symptoms and quality of life after stroke. J Neurol Sci 2006;247:149-56.

13. Gillen R, Tennen H, McKee TE, Gernert-Dott P, Affleck G. Depressive symptoms and history of depression predict rehabilitation efficiency in stroke patients. Arch Phys Med Rehabil 2001;82:1645-9.

14. Evers AW, Kraaimaat FW, van Lankveld W, Jongen PJ, Jacobs JW, Bijlsma WJ. Beyond unfavorable thinking: the Illness Cognition Questionnaire for chronic diseases. J Consult Clin Psychol 2001;69: 1026-36.
15. Rassart J, Luyckx K, Klimstra TA, Moons P, Groven C, Weets I. Personality and illness adaption in adults with type 1 diabetes: the intervening role of illness coping and perceptions. J Clin Psychol Med Settings 2014;21:41-55.

16. Peter C, Müller R, Cieza A, et al. Modeling life satisfaction in spinal cord injury: the role of psychological resources. Qual Life Res 2014; 23:2693-705.

17. Storor DL, Byrne GJ. Pre-morbid personality and depression following stroke. Int Psychogeriatr 2006;18:457-69.

18. Hwang SI, Choi KI, Park OT, Park S, Choi ES, Yi S. Correlations between premorbid personality and depression scales in stroke patients. Ann Rehabil Med 2011;35:328-36.

19. King RB, Shade-Zeldow Y, Carlson CE, Feldman JL, Philip M. Adaptation to stroke: a longitudinal study of depressive symptoms, physical health, and coping process. Top Stroke Rehabil 2002;9: 46-66.

20. Zenger M, Brix C, Borowski J, Stolzenburg J, Hinz A. The impact of optimism on anxiety, depression, and quality of life in urogenital cancer patients. Psychooncology 2010;19:879-86.

21. Mystakidou K, Parpa E, Tsilika E, et al. Self-efficacy, depression, and physical distress in males and females with cancer. Am J Hosp Palliat Care 2010;27:518-25.

22. Van Leeuwen CM, Post MW, Van Asbeck FW, et al. Life satisfaction in people with spinal cord injury during the first five years after discharge from inpatient rehabilitation. Disabil Rehabil 2012;34: 76-83.

23. Robinson-Smith G, Johnston MV, Allen J. Self-care self-efficacy, quality of life, and depression after stroke. Arch Phys Med Rehabil 2000;81:460-4.

24. Townend E, Tinson D, Kwan J, Sharpe M. 'Feeling sad and useless': an investigation into personal acceptance of disability and its association with depression following stroke. Clin Rehabil 2010;24: 555-64.

25. Johnson EA, Bakas T, Williams LS. Psychometric evaluation of the Appraisal of Health Scale in stroke survivors. J Nurs Meas 2011;19: 146-59.

26. Sinyor D, Amato P, Kaloupek DG, Becker R, Goldenberg M, Coopersmith H. Poststroke depression: relationships to functional impairment, coping strategies, and rehabilitation outcome. Stroke 1986;17:1102-7.

27. Boynton de Sepulveda LI, Chang B. Effective coping with stroke disability in a community setting: the development of a causal model. J Neurosci Nurs 1994;26:193-203.

28. Tielemans NS, Visser-Meily JM, Schepers VP, Post MW, van Heugten CM. Proactive coping post-stroke: psychometric properties of the Utrecht Proactive Coping Competence Scale. Arch Phys Med Rehabil 2014;95:670-5.

29. Van Mierlo ML, Van Heugten CM, Post MW, Lindeman E, De Kort PL, Visser-Meily JM. A longitudinal cohort study on quality of life in stroke patients and their partners: Restore4Stroke Cohort. Int J Stroke 2014;9:148-54.

30. Collin C, Wade DT, Davies S, Horne V. The Barthel ADL index: a reliability study. Int Disabil Stud 1988;10:61-3.

31. Meijer R, van Limbeek J, de Haan R. Development of the stroke-unit discharge guideline. Choice of assessment instruments for prediction in the subacute phase post-stroke. Int J Rehabil Res 2006;29:1-8.

32. Zigmond AS, Snaith RP. The Hospital Anxiety and Depression Scale. Acta Psychiatr Scand 1983;67:361-70.

33. Spinhoven PH, Ormel J, Sloekers PP, Kempen GI, Speckens AE, van Hemert AD. A validation study of the Hospital Anxiety and Depression Scale (HADS) in different groups of Dutch subjects. Psychol Med 1997;27:363-70.

34. De Wit L, Putman K, Baert I, et al. Anxiety and depression in the first six months after stroke. A longitudinal multicentre study. Disabil Rehabil 2008;30:1858-66.

35. Verhage F. [Intelligence and age: study among Dutch people from age 12 to 77] [Dutch]. Assen: Van Gorcum; 1964. 
36. Brott T, Adams HP, Olinger CP, et al. Measurements of acute cerebral infarction: a clinical examination scale. Stroke 1989;20:864-70.

37. Nasreddine ZS, Phillips NA, Bédirian V, et al. The Montreal Cognitive Assessment, MoCA: a brief screening tool for mild cognitive impairment. J Am Geriatr Soc 2005;3:695-9.

38. Sanderman R, Arrindell WA, Ranchor AV, Eysenck HJ, Eysenck SB. [Measuring personality traits with the Eysenck Personality Questionnaire (EPQ): an instruction manual] [Dutch]. Groningen: Noordelijk Centrum voor Gezondheidsvraagstukken; 1995.

39. Scheier MF, Carver CS, Bridges MW. Distinguishing optimism from neuroticism (and trait anxiety, self-mastery, and self-esteem): a reevaluation of the Life Orientation Test. J Pers Soc Psychol 1994;67:1063-78.

40. Scholz U, Doña BG, Sud S, Schwarzer R. Is general self-efficacy a universal construct? Psychometric findings from 25 countries. Eur J Psychol Assess 2002;18:242-51.

41. Bode C, Thoolen B, de Ridder D. [Measuring proactive coping competences: psychometric properties of the Utrecht Proactive Coping Competence List (UPCC)] [Dutch]. Psychol Gezond 2008;36:81-91.

42. Eriksen HR, Olff M, Ursin H. The CODE: a revised battery for coping and defense and its relation to subjective health. Scand J Psychol 1997;38:175-82.

43. Passier PE, Visser-Meily JM, van Zandvoort MJ, Post MW, Rinkel GJ, van Heugten C. Prevalence and determinants of cognitive complaints after aneurysmal subarachnoid hemorrhage. Cerebrovasc Dis 2010;29:557-63

44. Van der Werf SP, Evers A, Jongen PJ, Bleijenberg G. Helplessness as a mediator between neurological disability, emotional instability, experienced fatigue and depression in patients with multiple sclerosis. Mult Scler 2003;9:89-94.
45. Larsen RJ, Buss DM. Personality dispositions over time: stability, change, and coherence. In: Personality psychology: domains of knowledge about human nature. 2nd ed. New York: McGraw-Hill; 2005. p 138-40.

46. Caspi A, Roberts BW, Shiner RL. Personality development: stability and change. Annu Rev Psychol 2005;56:453-84.

47. Magee CA, Heaven PC, Miller LM. Personality change predicts selfreported mental and physical health. J Pers 2013;81:324-34.

48. Jones F, Mandy A, Partridge C. Changing self-efficacy in individuals following a first time stroke: preliminary study of a novel selfmanagement intervention. Clin Rehabil 2009;23:522-33.

49. Vriezekolk J, Eijsbouts A, Evers A, Stenger A, Van den Hoogen F, van Lankveld W. Poor psychological health status among patients with inflammatory rheumatic diseases and osteoarthritis in multidisciplinary rehabilitation: need for a routine psychological assessment. Disabil Rehabil 2010;32:836-44.

50. Evers AW, Kraaimaat FW, Van Riel PL, de Jong AJ. Tailored cognitive-behavioral therapy in early rheumatoid arthritis for patients at risk: a randomized controlled trial. Pain 2002;100:141-53.

51. Anson K, Ponsford J. Who benefits? Outcome following a coping skills group intervention for traumatically brain injured individuals. Brain Inj 2006;20:1-13.

52. Stalder-Lüthy F, Messerli-Bürgy N, Hofer H, Frischknecht E, Znoj H, Barth J. Effect of psychological interventions on depressive symptoms in long-term rehabilitation after an acquired brain injury: a systematic review and meta-analysis. Arch Phys Med Rehabil 2013; 94:1386-97.

53. Vaartjes I, Reitsma JB, De Bruin A, et al. Nationwide incidence of first stroke and TIA in the Netherlands. Eur J Neurol 2008;15:1315-23. 